Research Article

\title{
Experimental Investigation on Shear Strength and Liquefaction Potential of Rubber-Sand Mixtures
}

\author{
Zhou Enquan (iD) and Wang Qiong (iD) \\ Faculty of Civil Engineering and Mechanics, Jiangsu University, Zhenjiang 212013, China \\ Correspondence should be addressed to Zhou Enquan; enquan1986@126.com
}

Received 26 March 2019; Revised 12 June 2019; Accepted 16 June 2019; Published 2 July 2019

Academic Editor: Paolo Castaldo

Copyright ( 92019 Zhou Enquan and Wang Qiong. This is an open access article distributed under the Creative Commons Attribution License, which permits unrestricted use, distribution, and reproduction in any medium, provided the original work is properly cited.

The application of scrap tires as construction materials in civil engineering is one of the most promising ways to recycle this pollutant. The objective of this study was to investigate the shear strength and liquefaction potential of saturated rubber-sand mixtures. Direct shear tests and cyclic triaxial tests were conducted on rubber-sand mixtures at various rubber contents. It was found that the addition of rubber particles to sand changed the shear stress-horizontal displacement development. The addition of rubber particles to sand improved the shear strength slightly and improved resistance to liquefaction significantly. Additionally, a hyperbolic model was proposed to describe the pore water pressure generation. This study demonstrates the effect of rubber particles on the physical properties of sand.

\section{Introduction}

With the rapid development of automobile industry, discarded automobile tires have become a serious threat to the environment. If these wastes are not handled properly, they will cause environmental pollution, fire, and harm to people's health. For example, in 1999, millions of scrap tires spontaneously ignited in Stanislaus, USA [1].

Lately, several investigations have been undertaken in order to study the possibilities of application of rubber-sand mixtures in civil engineering, as reported by Cetin et al. [2]. The investigations show that the rubber-sand mixtures have the advantages of low bulk density, high physical and chemical durability, high tensile strength, and high shear strength and permeability compared with pure sand [3]. Therefore, the rubber-sand mixtures have been widely used in highway embankments as a lightweight fill material and backfills behind retaining structures over weak or compressible soils [4-6] and also been used in energy dissipation cushions of dynamical foundations or building bases to reduce vibration and seismic dynamic effects, as reported by Tsang [7] and Abdelhaleem et al. [8].

Researchers have carried out extensive research studies on the mechanical properties of rubber-sand mixtures, which have made many useful conclusions and actively promote the engineering application of rubber-sand mixtures.

Previous researchers mainly conducted direct shear tests on the dry or slightly moist rubber-sand mixtures, and they did not reach consensus on the research of shear strength of rubber-sand mixtures. The addition of rubber particles or tire chips in sand was reported to improve the shear strength of sand [9-13]. On the contrary, the addition of rubber particles or tire chips in sand was reported to reduce the shear strength of sand, as discussed by Tanchaisawat et al. [14]. Moreover, Mahmoud [15] discovered that the internal friction angle of rubber-sand mixtures which contain $10 \%-20 \%$ granulated rubber immensely improved, while the shear strength of the mixtures did not change a lot. Sellaf et al. [16] conducted direct shear tests on the mixtures of dry rubber tires and sediments, and the results indicated that there is a decrease in cohesion with the increase of scrap tire rubber when the variation of internal friction angle is vacillating.

In the recent years, several studies were carried out on the dynamic behaviour of rubber-sand mixtures. However, the research results remain controversial. The addition of rubber particles or tire chips in sand was reported to 
improve the resistance to liquefaction of saturated sand [17-20], while some other studies [21, 22] gave the opposite point of view. Moreover, Mashiri et al. [23] conducted strain-controlled cyclic triaxial tests on the sand-tire chip mixtures, and the results indicated that the addition of $10 \%$ of tire chips to sand does not improve the resistance to liquefaction. The addition of tire chips between $10 \%$ and $30 \%$ to sand improves the resistance to liquefaction significantly. The addition of tire chips between $30 \%$ and $40 \%$ to sand reduces the resistance to liquefaction significantly. Shariatmadari et al. [24] conducted hollow torsional tests on the sand-tire crumb mixtures, and the results indicated that the addition of $10 \%$ of tire chips to sand decreases the resistance to liquefaction and the addition of tire chips between $10 \%$ and $25 \%$ to sand decreases the resistance to liquefaction.

The objective of the present study is to study the shear strength and liquefaction potential of liquefiable sand mixed with rubber particles. The strain-controlled direct shear tests were conducted on saturated rubber-sand mixtures to determine their shear strength. And stresscontrolled undrained cyclic triaxial tests were carried out on saturated rubber-sand mixtures to determine their liquefaction potential.

\section{Materials and Methods}

2.1. Materials Used. The tests were conducted on rubbersand mixtures, composed of sand and rubber particles. Sand here refers to Fujian sand, which has been used in numerous studies in the geotechnical field in China. The maximum and minimum dry densities of Fujian sand are $18.53 \mathrm{kN} / \mathrm{m}^{3}$ and $16.01 \mathrm{kN} / \mathrm{m}^{3}$, respectively. The rubber shreds were obtained by shredding scrap tires with the help of a mechanized shredding machine. To prevent any puncture of membranes, the steel wires in the rubber tires were removed before shredding. The diameter of the rubber shreds ranged from 1 to $5 \mathrm{~mm}$. The rubber shreds were classified as rubber particles according to ASTM D6270-08 (2012) [25]. Physical properties of the sand and rubber particles used in the tests are shown in Table 1. The grain size distributions of the sand and rubber particles are presented in Figures 1 and 2. The optical microscope images of the sand and rubber particles are presented in Figure 3. Figure 3(a) shows the contact form between the sand and rubber particles of the mixture specimen. Figures 3(b) and 3(c) show the surface state of sand and rubber, respectively.

\subsection{Sample Preparation and Testing Program for Direct} Shear Tests. The effects of the rubber particle content (RC) on the shear strength of saturated rubber-sand mixtures were studied in these direct shear tests. The direct shear tests were conducted in a strain-controlled direct shear apparatus. The size of all sand-rubber samples is $61.8 \mathrm{~mm}$ in diameter and $20 \mathrm{~mm}$ in height. The tests were carried out based on the procedure described by the Chinese standard for the soil test method (GB/T 50123-1999) [26]. Direct shear tests were performed on samples at four normal stresses $\sigma_{\mathrm{n}}$ of $100 \mathrm{kPa}, 200 \mathrm{kPa}, 300 \mathrm{kPa}$, and $400 \mathrm{kPa}$ and at a shear displacement rate of $2.4 \mathrm{~mm} / \mathrm{min}$. Samples consisting of sand alone and various mixtures of sand and rubber were tested. The mixtures contained 5\%, 10\%, and $15 \%$ rubber particles by weight. The relative density of pure sand is $50 \%$, and the mass is $104.42 \mathrm{~g}$. The sand-rubber mixtures were divided into three parts. Each part was poured in the shear test box and compacted in the dry state in order to reach the required relative density. The compacted specimens were placed in the saturator for 2 hours to make sure that the specimens were adequately filled with deaired water before shearing.

2.3. Sample Preparation and Testing Program for Cyclic Triaxial Tests. The effects of the rubber particle content on the dynamic characteristics of saturated rubber-sand mixtures were studied in stress-controlled cyclic triaxial tests. The size of all sand-rubber samples is $39.1 \mathrm{~mm}$ in diameter and $80 \mathrm{~mm}$ in height. The tests were carried out based on the procedure described by the Chinese standard for the soil test method (GB/T 50123-1999) [26]. Samples consisting of sand alone and various mixtures of sand and rubber were tested. The mixtures contained 3\%, 5\%, and $10 \%$ rubber particles by weight. The relative density of pure sand is $45 \%$, and the mass is $163.82 \mathrm{~g}$. The sand-rubber mixtures were divided into four parts. Each part was deposited into the mold and compacted in the dry state in order to reach the required relative density. After sample preparation, the specimens were installed with a chamber pressure of $50 \mathrm{kPa}$ and a back pressure of $30 \mathrm{kPa}$. For the saturation process, distilled deaired water was flushed into specimens from the bottom and circulated at least one hour to ensure that the specimens were fully saturated. The $B$ value of any prepared specimens was required to be $>0.95$. The specimens were consolidated at an effective confining pressure of $50 \mathrm{kPa}$, $100 \mathrm{kPa}$, and $200 \mathrm{kPa}$. The undrained cyclic tests were carried out at a constant frequency of $1 \mathrm{~Hz}$. The testing program performed with and without granulated rubber is summarized in Table 2. The pore water pressure ratio (PWPR) to effective confining pressure at 1 was the threshold standard if initial liquefaction is adopted in this paper.

The cyclic stress ratio (CSR) in Table 2 is calculated by the following equation:

$$
\operatorname{CSR}=\frac{\sigma_{\mathrm{d}}}{2 \sigma_{3}^{\prime}}
$$

where $\sigma_{3}^{\prime}$ is the effective confining pressure and $\sigma_{\mathrm{d}}$ is the cyclic axial stress.

\section{Direct Shear Stress Test Results}

Figure 4 shows the shear stress-horizontal displacement curves for pure sand and rubber-sand mixtures at normal stresses of 100, 200, 300, and $400 \mathrm{kPa}$. It can be observed that the curves for pure sand and mixtures with different rubber contents are obviously different. The shear stress- 
TABle 1: Physical properties of the Fujian sand and rubber particles used in the tests.

\begin{tabular}{|c|c|c|c|c|c|c|}
\hline Materials & $\begin{array}{c}\text { Mean diameter } \\
d_{50}(\mathrm{~mm})\end{array}$ & $\begin{array}{l}\text { Uniformity coefficient } \\
\qquad C_{\mathrm{u}}=d_{60} / d_{10}\end{array}$ & $\begin{array}{c}\text { Curvature coefficient } \\
C_{\mathrm{c}}=d_{30}^{2} /\left(d_{10} d_{60}\right)\end{array}$ & $\begin{array}{l}\text { Maximum void } \\
\text { ratio } e_{\max }\end{array}$ & $\begin{array}{l}\text { Minimum void } \\
\text { ratio } e_{\min }\end{array}$ & Specific gravity $G_{\mathrm{s}}$ \\
\hline Fuj & 0.65 & 7.41 & 0.43 & 0.67 & 0.45 & 2.68 \\
\hline Rubber particles & 3.10 & 1.48 & 0.88 & 1.32 & 0.74 & 1.21 \\
\hline
\end{tabular}

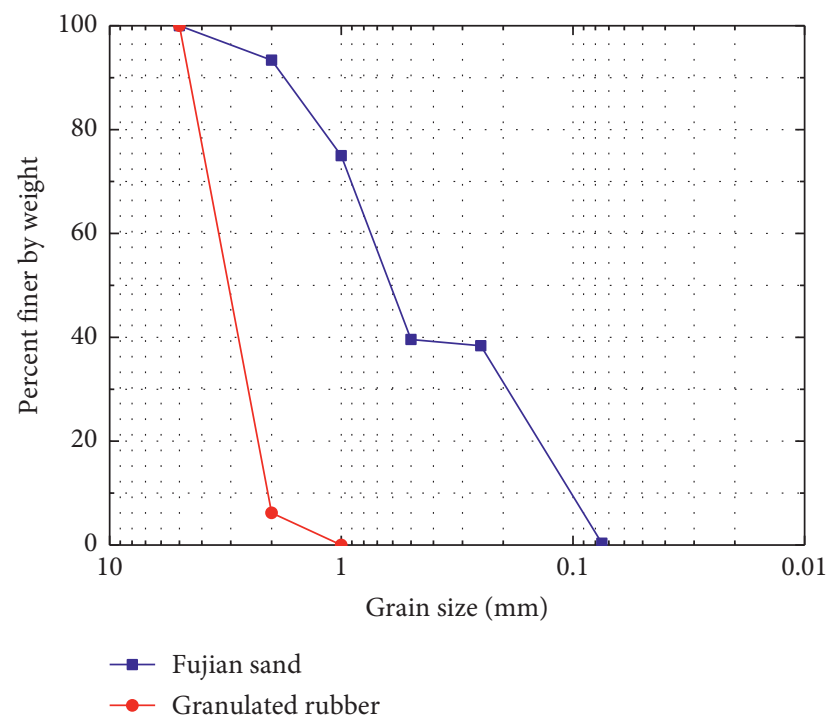

Figure 1: Grain size distribution of the Fujian sand and granulated rubber material used in the tests.

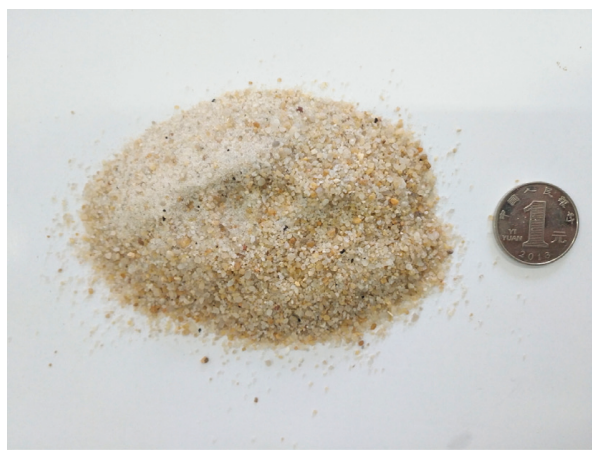

(a)

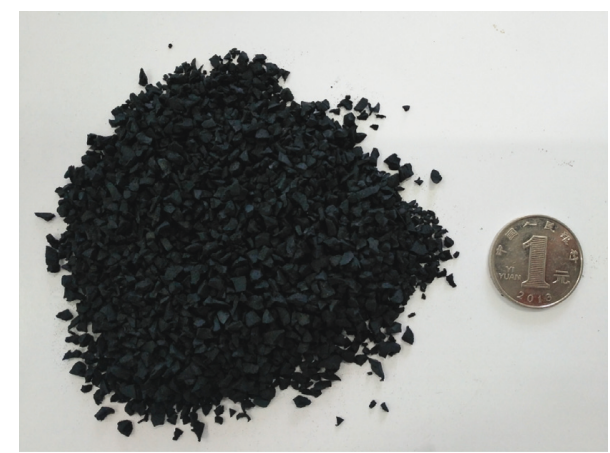

(b)

Figure 2: Materials tested. (a) Fujian sand. (b) Rubber particles.

horizontal displacement curves for pure sand show a clear peak associated with failure, and the curves exhibit a strainsoftening characteristic, as shown in Figure 4(a). The shear stress-horizontal displacement curves for mixtures with different rubber contents exhibit a strain-hardening characteristic without peak value, as shown in Figures 4 (b) 4(d). The reason for difference between pure sand and mixtures is that adding rubber particles to sand increases its elasticity and compressibility. As a result, the rubber-sand mixtures exhibit shear-shrinking and strain-hardening behaviours.

In order to study the effects of normal stress and rubber particle content on the shear strength, the shear strength of samples under different conditions is presented in Figure 5.
In these cases, shear strength was reported as the peak shear stress. However, for most cases, a peak shear stress was not reached after $6 \mathrm{~mm}$ of horizontal displacement, as shown in Figure 4. Generally, in samples for which no peak shear stress was observed, shear stress at a horizontal displacement of $6 \mathrm{~mm}$ was reported as the shear strength according to the Chinese standard for the soil test method (GB/T 501231999) [26]. The test results show that the shear strength is positively correlated with the normal stress $\sigma_{\mathrm{n}}$ and increases steadily with the increase of the normal stress $\sigma_{\mathrm{n}}$. The addition of rubber particles to sand improves the shear strength of sand. The shear strength of samples grows with the increase of the rubber content, but the growth rate is slight. 


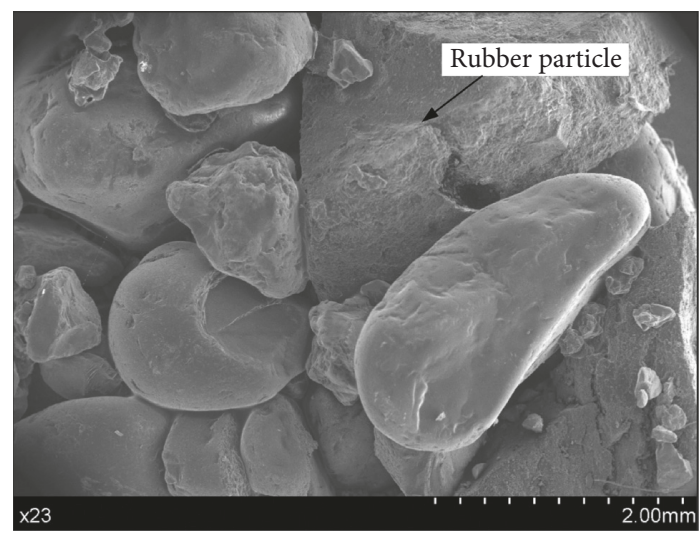

(a)

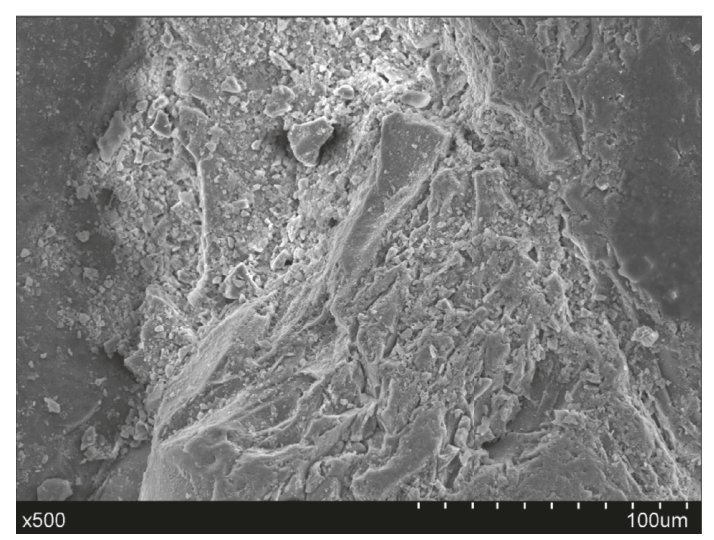

(b)

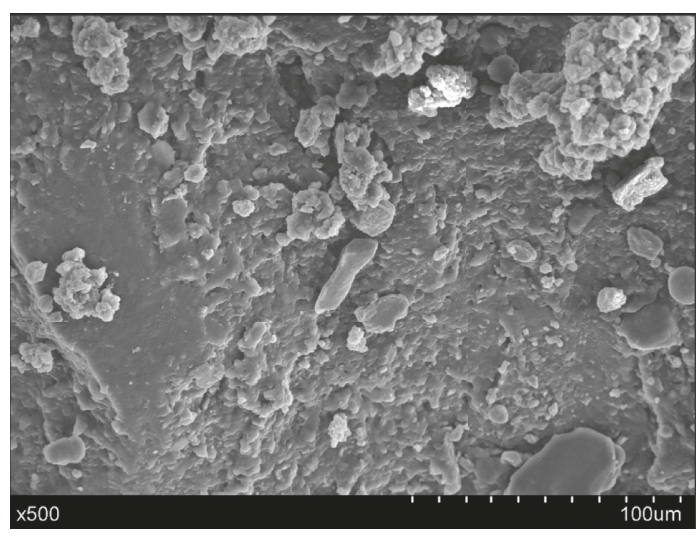

(c)

Figure 3: Optical microscope images. (a) Contact form between the sand and rubber particles. (b) Surface state of sand. (c) Surface state of rubber.

TABLE 2: Test cases for the cyclic triaxial tests.

\begin{tabular}{|c|c|c|c|c|}
\hline Test ID & $\begin{array}{c}\text { Rubber } \\
\text { content }(\%)\end{array}$ & $\begin{array}{c}\text { Effective confining } \\
\text { pressure }(\mathrm{kPa})\end{array}$ & $\begin{array}{l}\text { Cyclic axial } \\
\text { stress }(\mathrm{kPa})\end{array}$ & CSR \\
\hline B1 & 0 & 100 & 20 & 0.1 \\
\hline B2 & 0 & 100 & 40 & 0.2 \\
\hline B3 & 0 & 100 & 60 & 0.3 \\
\hline B4 & 0 & 100 & 80 & 0.4 \\
\hline B5 & 0 & 100 & 100 & 0.5 \\
\hline B6 & 3 & 100 & 40 & 0.2 \\
\hline B7 & 3 & 100 & 60 & 0.3 \\
\hline B8 & 3 & 100 & 80 & 0.4 \\
\hline B9 & 3 & 100 & 100 & 0.5 \\
\hline $\mathrm{B} 10$ & 5 & 50 & 20 & 0.2 \\
\hline B11 & 5 & 50 & 30 & 0.3 \\
\hline B12 & 5 & 50 & 40 & 0.4 \\
\hline B13 & 5 & 100 & 40 & 0.2 \\
\hline B14 & 5 & 100 & 60 & 0.3 \\
\hline B15 & 5 & 100 & 80 & 0.4 \\
\hline B16 & 5 & 100 & 100 & 0.5 \\
\hline B17 & 5 & 200 & 80 & 0.2 \\
\hline B18 & 5 & 200 & 120 & 0.3 \\
\hline B19 & 5 & 200 & 160 & 0.4 \\
\hline B20 & 10 & 100 & 40 & 0.2 \\
\hline B21 & 10 & 100 & 60 & 0.3 \\
\hline B22 & 10 & 100 & 80 & 0.4 \\
\hline B23 & 10 & 100 & 100 & 0.5 \\
\hline
\end{tabular}

In order to study the shear strength behaviour of pure sand and rubber-sand mixtures, internal friction angle and cohesion of the samples were analyzed according to Mohr-Coulomb criteria, as shown in Figure 6. With the consideration of uncertainties in the model and test, the uncertainty factor $\theta$ should be identified using equation (2) and the effect of uncertainty can be expressed in terms of coefficients of variation as equation $(3)$ [27, 28]:

$$
\theta_{h}=\frac{R_{\text {experimental }, h}}{R_{\text {model }, h}}
$$

where $R_{\text {experimental, } h}$ is the $h$ th experimental result, $R_{\text {model }, h}$ is the $h$ th model prediction, and $\theta_{h}$ is the $h$ th model uncertainty.

$$
v_{\theta} \approx \sqrt{v_{\text {observed }}^{2}-v_{\varepsilon}^{2}}
$$

where $v_{\theta}$ is the coefficient of variation of model uncertainty, $v_{\text {observed }}$ is the coefficient of variation as derived from comparison of model and experimental results, and $v_{\varepsilon}$ is the coefficient of variation of test uncertainty. The coefficient of variation of model uncertainty is 0.09 (approximate to 0.1), and the test uncertainty has minor significance, as described by Holicky et al. [28] and Sykora et al. [29]. In this study, the coefficient of variation of test uncertainty $v_{\varepsilon}$ is not considered. 


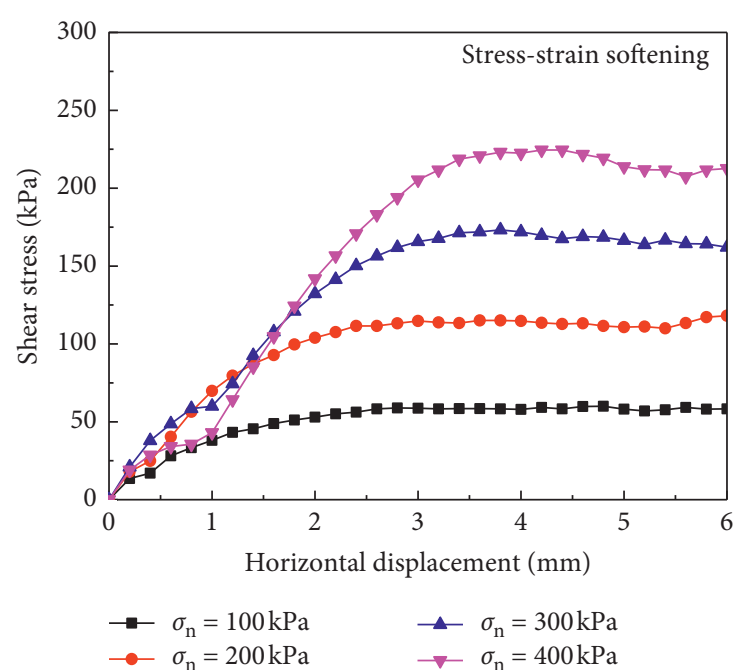

(a)

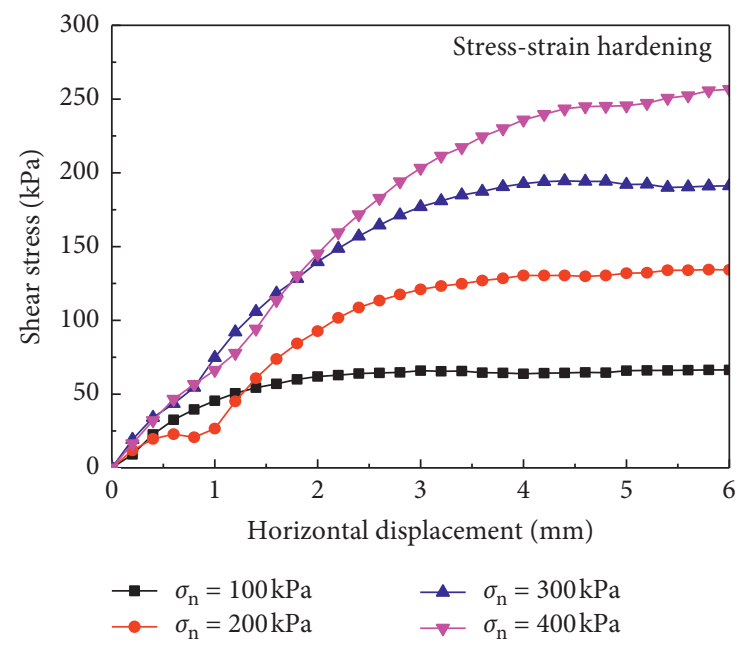

(c)

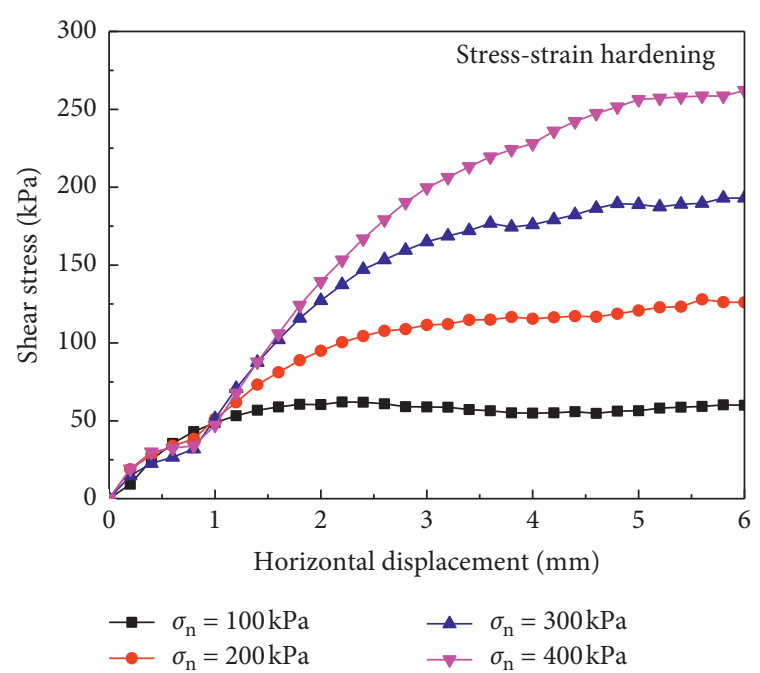

(b)

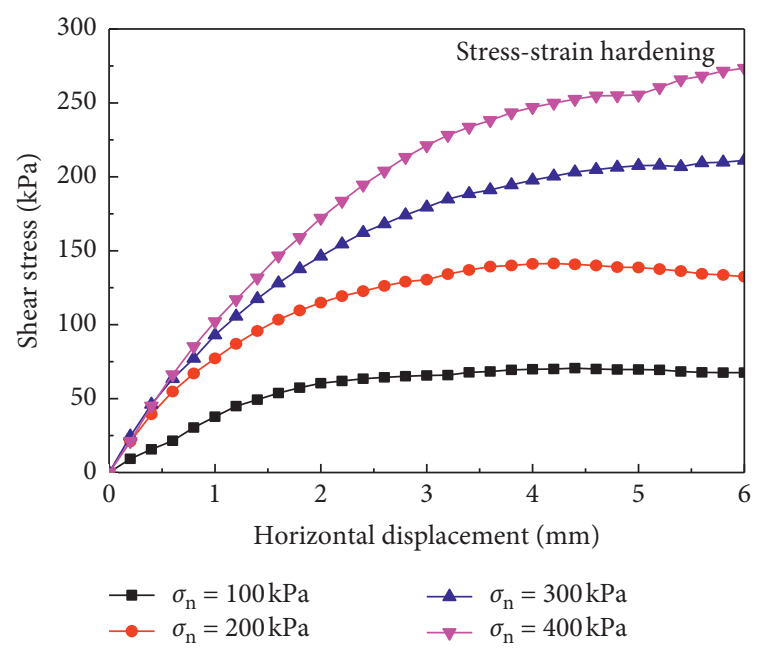

(d)

Figure 4: Shear stress-horizontal displacement curves. Rubber content: (a) 0\%; (b) 5\%; (c) 10\%; (d) $15 \%$.

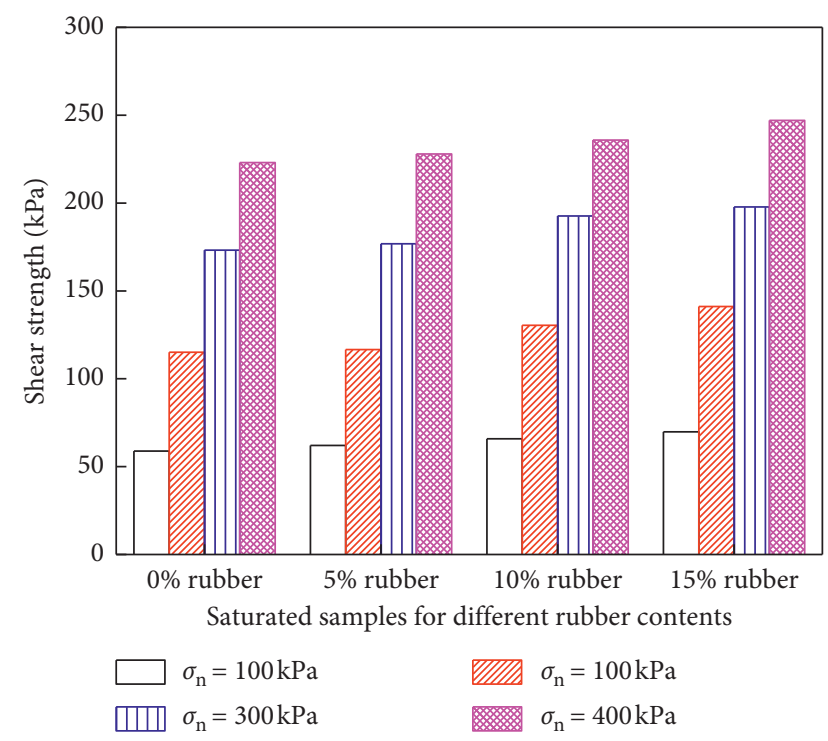

FIGURE 5: Shear strength of saturated samples.
The model uncertainty observations $\theta$ are shown in Figure 6(b), while the mean of $\theta$ is 0.93 and the coefficient of variation of model uncertainty $v_{\theta}$ is 0.09 .

Figure 7 reveals the relationship between internal friction angle and rubber particle content and the relationship between cohesion and rubber particle content. It can be observed that adding rubber particles to sand increases its internal friction angle and cohesion. The cohesion of the saturated rubber-sand sample increases with the increase of rubber content, and the internal friction angle increases slightly with the increase of rubber content.

\section{Cyclic Triaxial Test Results}

4.1. Liquefaction Potential. The typical experimental results are shown in Figures 8-10. Figures 8(a), 9(a), and 10(a) show the loops of the axial stress and axial strain for three different confining pressures. Figures 8(b), 9(b), and 10(b) show the time histories of the pore water pressure ratio (PWPR). Overall, the slopes of the axial stress and axial strain decrease 


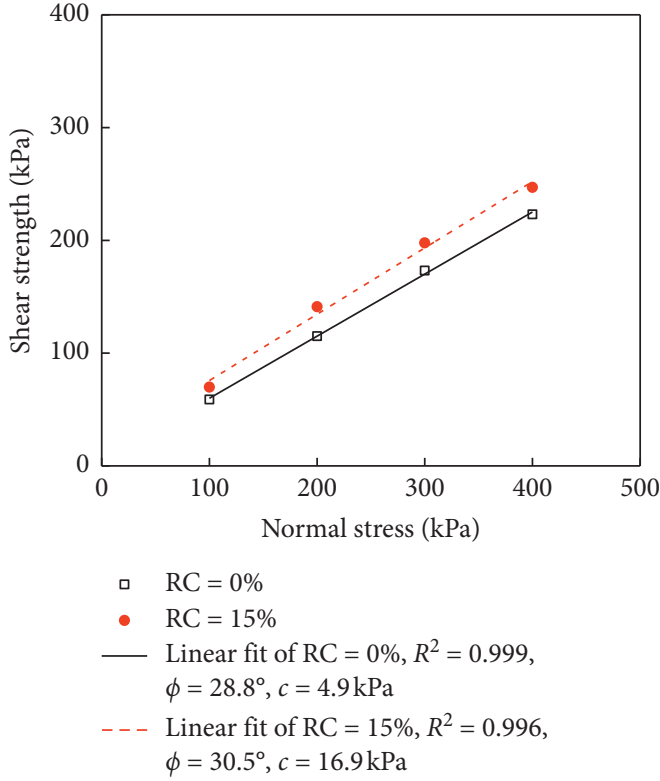

(a)

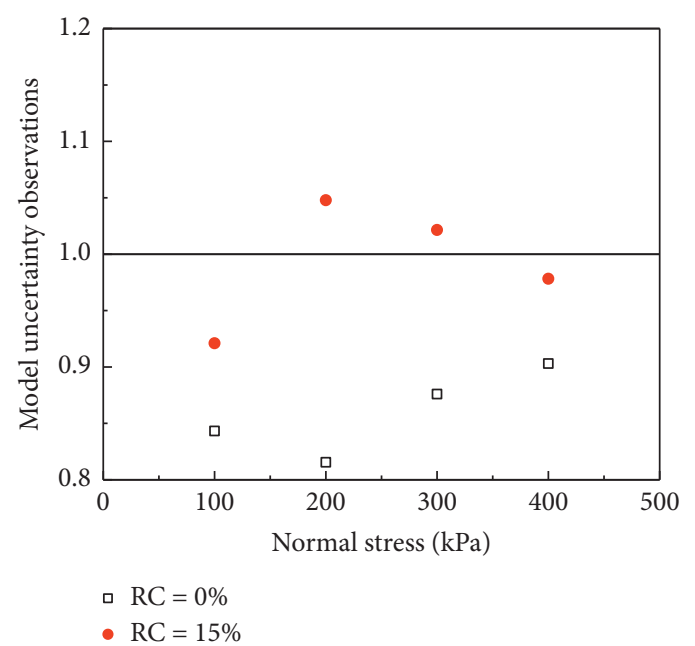

(b)

Figure 6: Calculations of cohesion and internal friction angle through Mohr-Coulomb criteria. (a) Fitting results. (b) Model uncertainty observations $\theta$ versus normal stress.

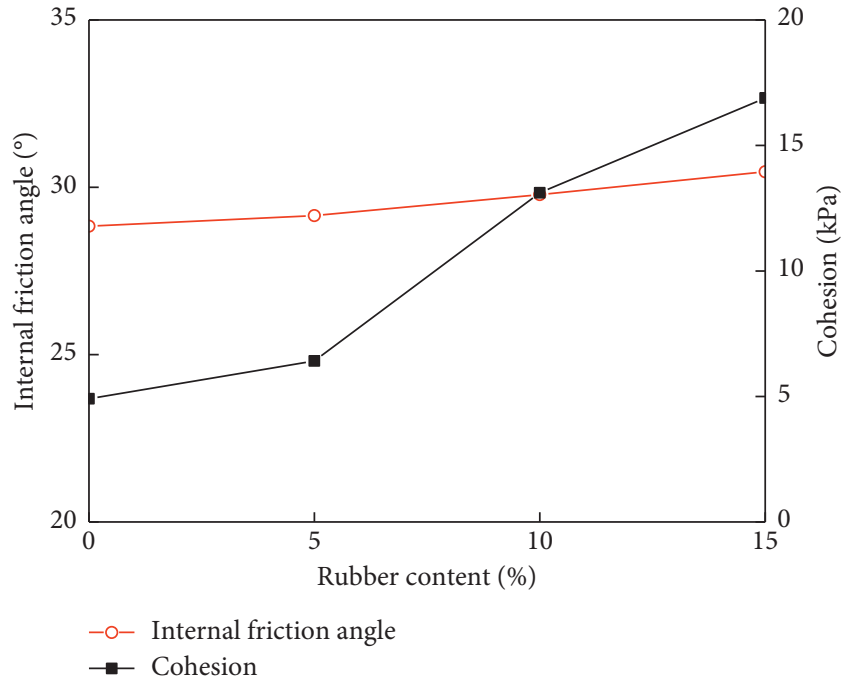

Figure 7: Relationship between internal friction angle, cohesion, and rubber content.

gradually with increasing numbers of loading cycles. The areas of the axial stress and axial strain loops increase gradually with increasing numbers of loading cycles, indicating the dissipated energy and damping increase. The stiffness decreases with increasing axial strain. The PWPR spikes obviously show a tendency to increase rapidly and positive and negative fluctuations or oscillating characteristics under cyclic loading, indicating the alternating behaviour of shear expansibility and compressibility during cyclic loading.

The effect of CSR on the number of cycles to liquefaction $\left(N_{f}\right)$ for different rubber content mixtures at an effective confining pressure of $100 \mathrm{kPa}$ is shown in Figure 11(a). The test results clearly reveal that the number of cycles required to reach liquefaction increases with the decreasing CSR. Moreover, for a particular value of $N_{f}$, the CSR for liquefaction increases with the increasing rubber content (RC) from $0 \%$ to $10 \%$. The results reveal that the addition of rubber to sand improves the resistance to liquefaction significantly.

Figure 11(b) shows the effect of effective consolidation pressure on the relationship between the CSR and the number of cycles $\left(N_{f}\right)$. The test results reveal that the effective confining pressure had little influence on the correlation between the CSR and $N_{f}$.

The relationship between the CSR and the number of cycles $\left(N_{f}\right)$ of pure sand and sand with various rubber particles during the dynamic axial loading is closely related to the rubber content (RC), and the correlation between the CSR and $N_{f}$ can be described by the following equation:

$$
\mathrm{CSR}=m N_{f}^{n}
$$

where parameters $m$ and $n$ are fitting values, which are listed in Table 3 for different test cases. The $n$ value is constant for different cases, and the $m$ value is closely related to rubber content (RC). Figure 12 shows that the correlation between the parameter $m$ and the rubber content (RC) can be expressed as

$$
m=0.09 \mathrm{RC}+0.57
$$

where RC is the rubber content (\%).

Therefore, equation (4) can also be expressed as

$$
\mathrm{CSR}=(0.09 \mathrm{RC}+0.57) N_{f}^{(-0.32)} .
$$




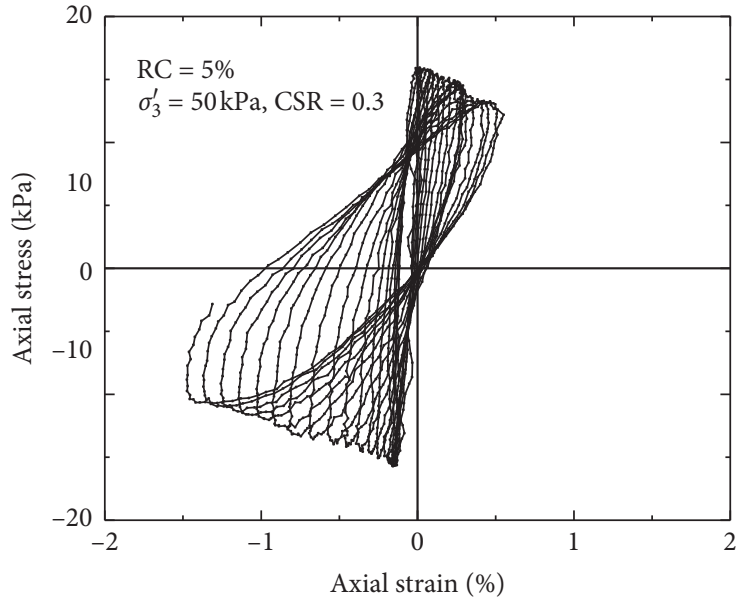

(a)

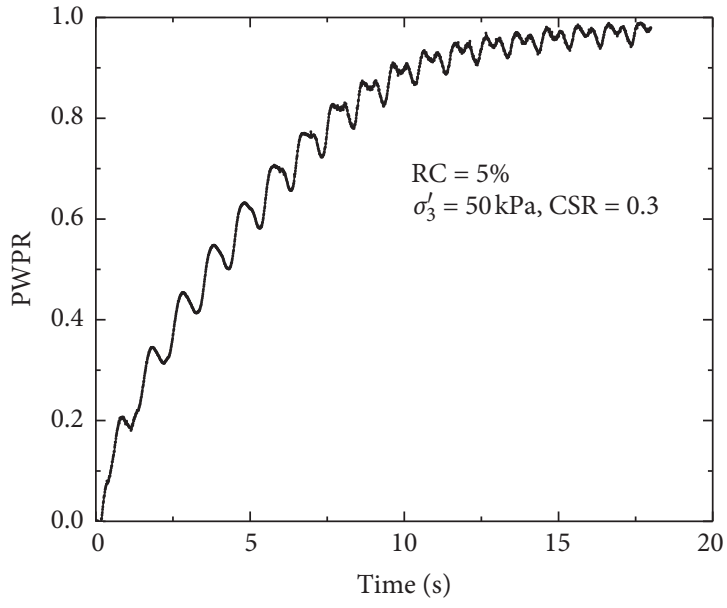

(b)

Figure 8: Typical experimental results for $\mathrm{RC}=5 \%, \sigma_{3}^{\prime}=50 \mathrm{kPa}$, and CSR $=0.3$. (a) Loops of the axial stress and axial strain. (b) Time histories of PWPR.

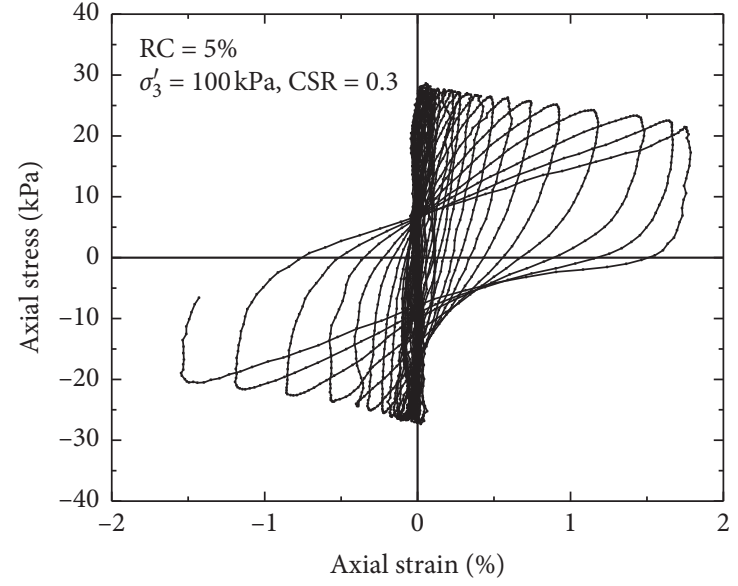

(a)

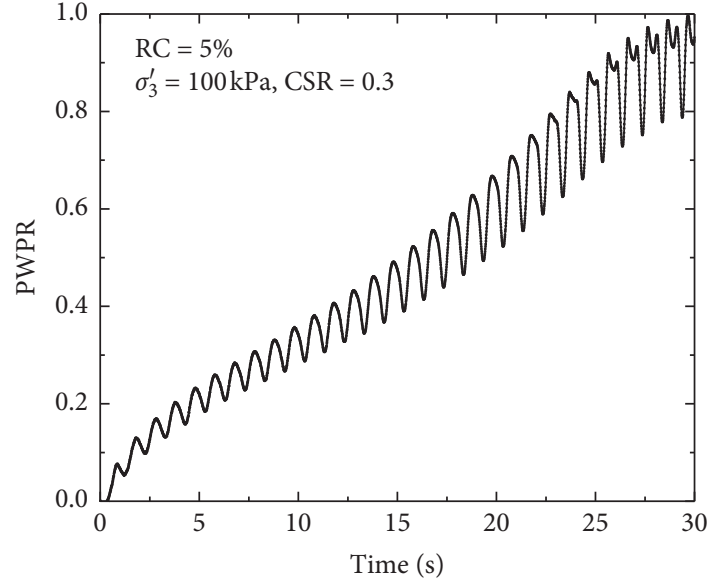

(b)

FIGURE 9: Typical experimental results for $\mathrm{RC}=5 \%, \sigma_{3}^{\prime}=50=100 \mathrm{kPa}$, and CSR $=0.3$. (a) Loops of the axial stress and axial strain. (b) Time histories of PWPR.

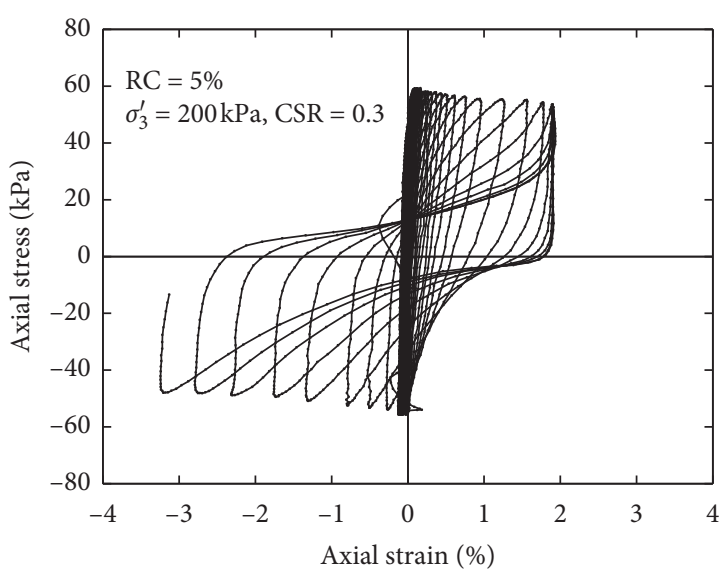

(a)

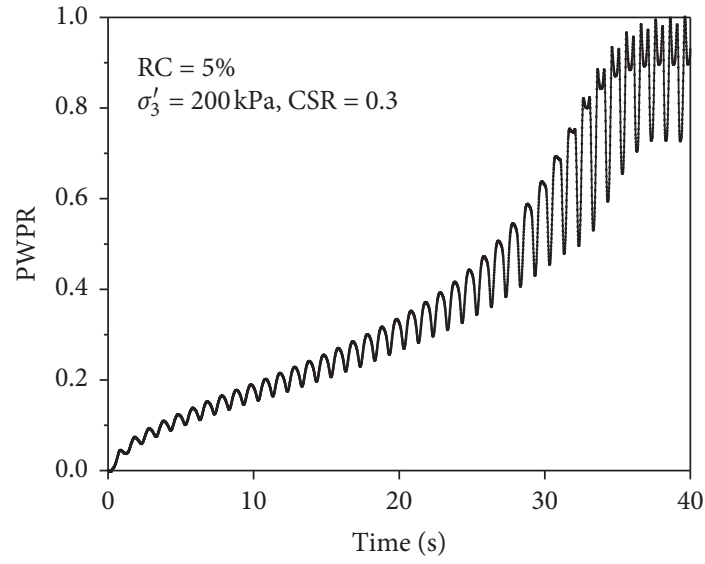

(b)

FIgURE 10: Typical experimental results for $\mathrm{RC}=5 \%, \sigma_{3}^{\prime}=200 \mathrm{kPa}$, and CSR $=0.3$. (a) Loops of the axial stress and axial strain. (b) Time histories of PWPR. 


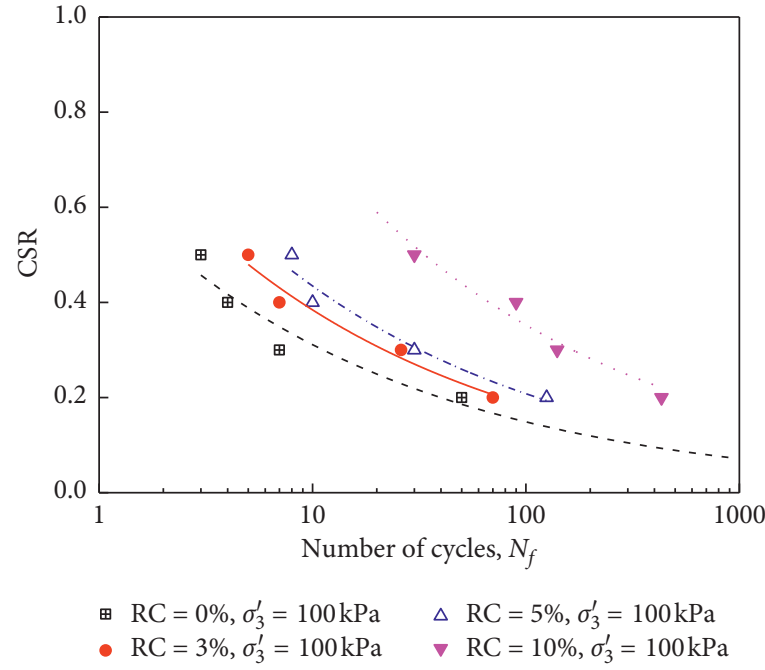

(a)

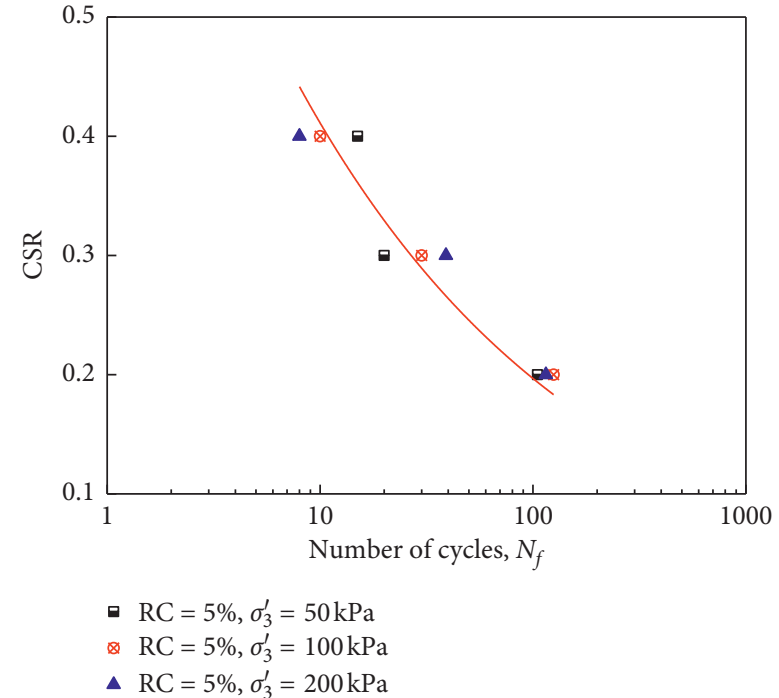

(b)

Figure 11: Relationship between CSR and $N f$ for different rubber contents (a) and for different effective confining pressures (b).

TABLE 3: Fitting values of $m$ and $n$ for different test cases.

\begin{tabular}{lccc}
\hline Rubber content (\%) & \multicolumn{3}{c}{ Parameters } \\
& $m$ & -0.32 & $R^{2}$ \\
\hline 0 & 0.65 & -0.32 & 0.95 \\
3 & 0.80 & -0.32 & 0.96 \\
5 & 0.91 & -0.32 & 0.95 \\
10 & 1.54 & 0.98 \\
\hline
\end{tabular}

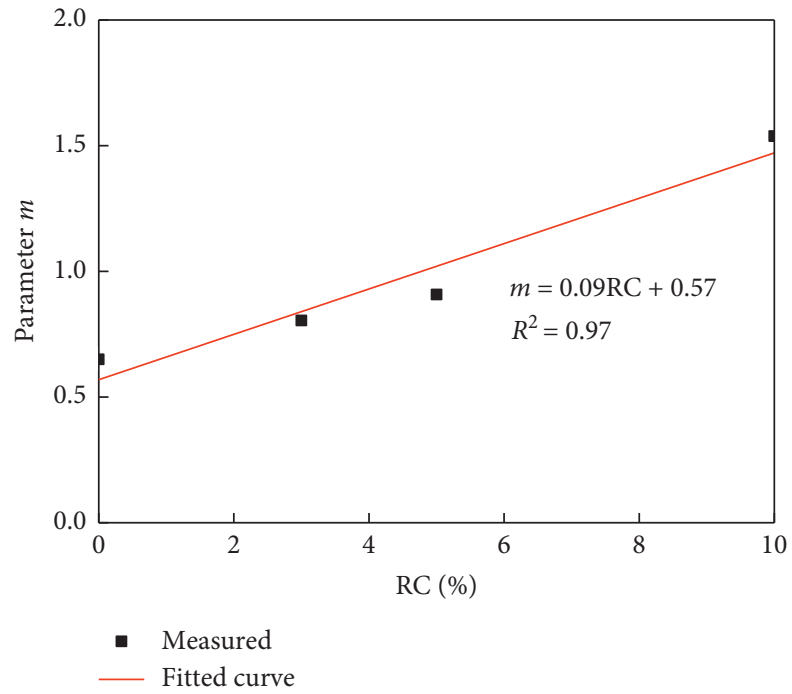

FIGURE 12: Fitting correlation between the parameter $m$ and the rubber content.

Then, Figure 13 shows the fitting correlation between CSR/ $0.09 \mathrm{RC}+0.57)$ and the number of cycles $\left(N_{f}\right)$ for all test cases. Figure 13(a) shows the fitting results. Figure 13(b) shows model uncertainty observations $\theta$ versus RC, while the mean of $\theta$ is 1.16 and the coefficient of variation of model uncertainty $v_{\theta}$ is 0.49 .
4.2. Pore Water Pressure Development. Figure 14 shows the pore water pressure generation for different test cases. The test results reveal that the pore water pressure generation is influenced by the rubber content, CSR, and effective consolidation pressure. The correlation between the PWPR and $N / N_{f}$ can be described by the following equation: 

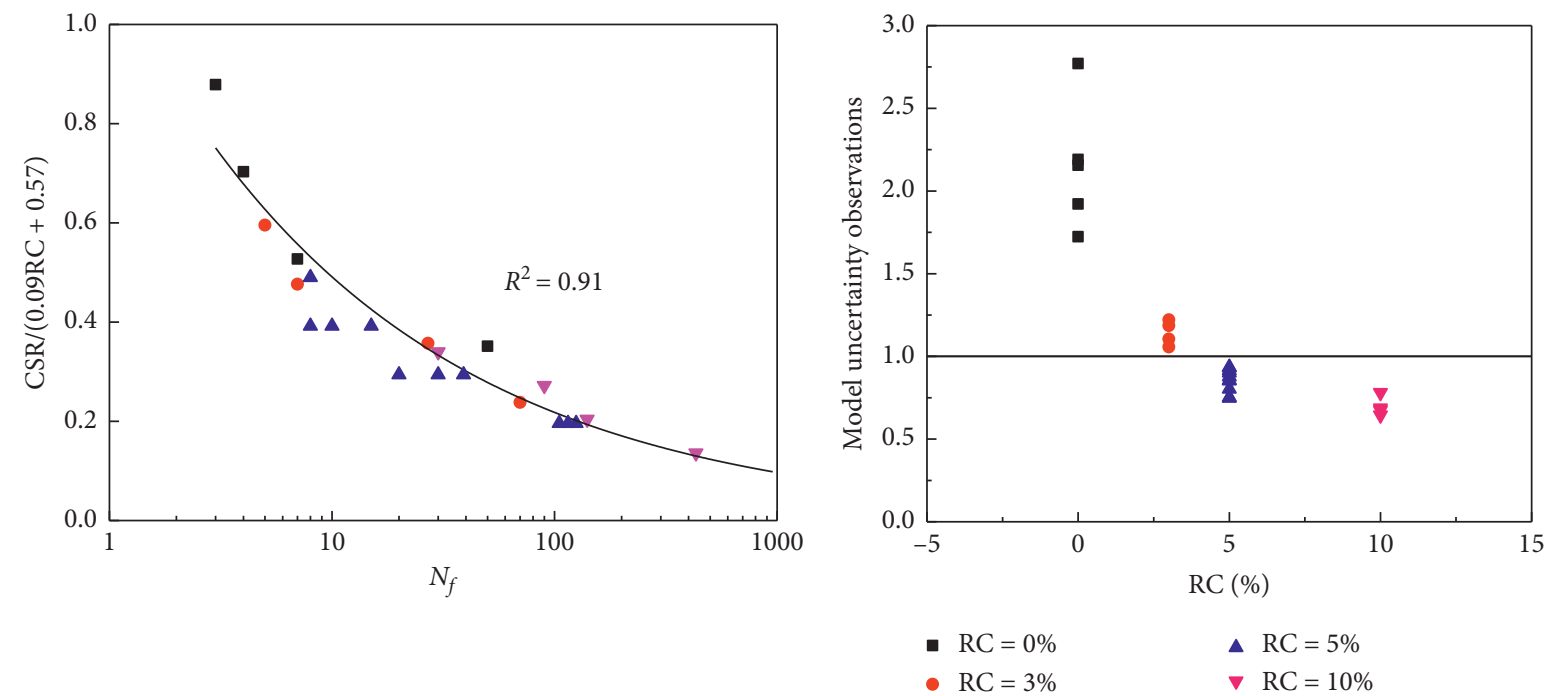

(a)

(b)

FiguRE 13: Fitting correlation between CSR/ $(0.09 R C+0.57)$ and the number of cycles $\left(N_{f}\right)$ for all test cases. (a) Fitting results. (b) Model uncertainty observations $\theta$ versus RC.

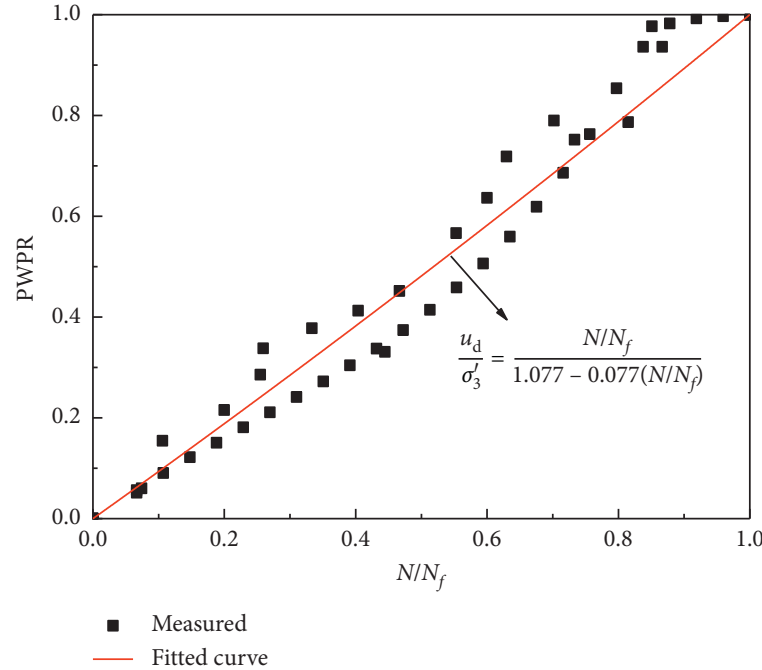

(a)

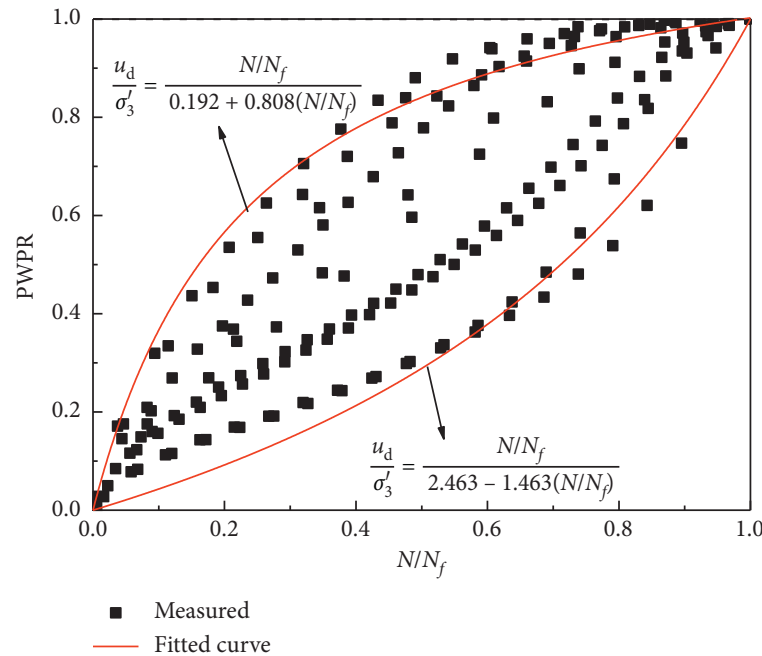

(c)

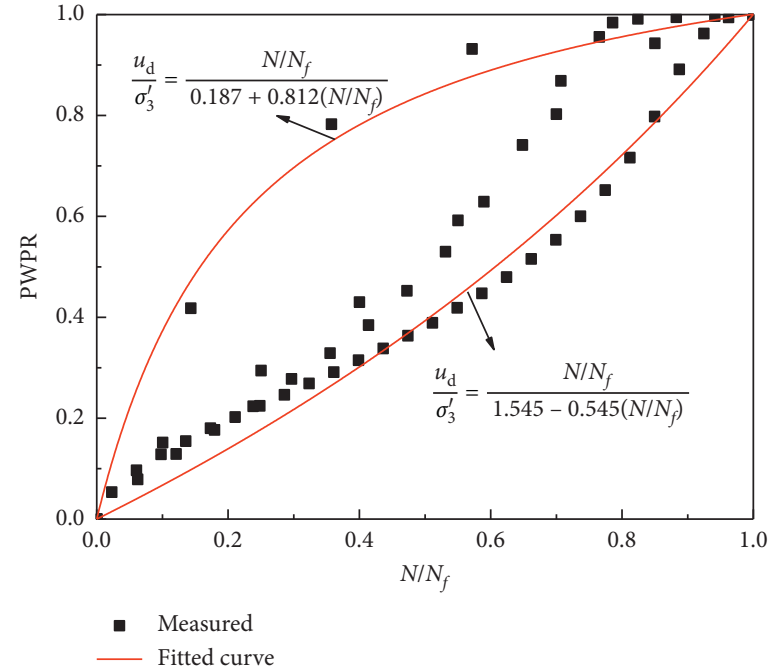

(b)

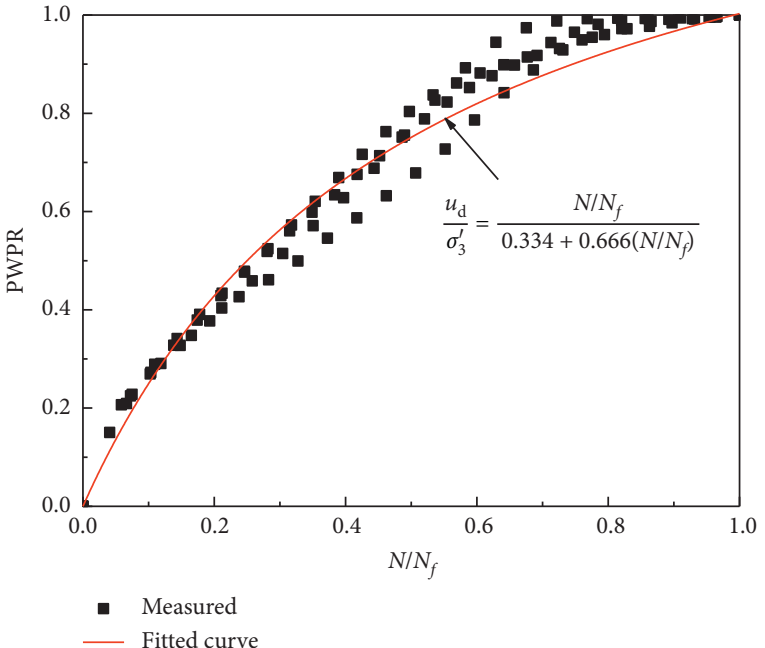

(d)

FiguRe 14: Pore water pressure ratio (PWPR) for different rubber content cases for (a) RC=0\%, (b) RC=3\%, (c) RC = 5\%, and (d) RC = 10\%. 


$$
\frac{u_{\mathrm{d}}}{\sigma_{3}^{\prime}}=\frac{N / N_{f}}{T_{1}+T_{2}\left(N / N_{f}\right)},
$$

where $u_{\mathrm{d}}$ is the pore water pressure, $N$ is the number of vibration cycles, and $T_{1}$ and $T_{2}$ are the fitting parameters.

\section{Conclusions}

The rubber-sand mixtures were adopted to investigate the shear strength characteristics and liquefaction potential of the saturated composite material. The shear strength characteristics of the saturated mixtures were obtained by the strain-controlled direct shear tests. The liquefaction potential of the saturated mixtures was investigated by the stress-controlled undrained cyclic triaxial tests. From the test results, the following conclusions can be drawn:

(1) The deformable ability of the rubber-sand mixture is enhanced due to the elasticity of rubber particles. The distribution of shear stress with horizontal displacement of pure sand reflects the characteristic of strain softening, while the distribution of rubber-sand mixtures reflects the characteristic of strain hardening.

(2) The shear strength of samples increases with the increasing normal stress, and the addition of rubber particles to sand improves the shear strength of sand. The shear strength of samples increases with the increase of the rubber content. The addition of rubber particles to sand increases its internal friction angle and cohesion.

(3) The addition of rubber to sand improves the resistance to liquefaction significantly. The effective confining pressure had little influence on the correlation between the cyclic stress ratio and the number of cycles. A power function model was presented to describe the correlation between the CSR and $N_{f}$ of saturated mixtures under cyclic loading.

(4) The PWPR spikes obviously show a tendency to increase rapidly and positive and negative fluctuations or oscillating characteristics under cyclic loading. A hyperbolic model was presented to describe the relation between the PWPR and $N / N_{f}$ of saturated mixtures under cyclic loading.

\section{Data Availability}

The data used to support the findings of this study are available from the corresponding author upon request.

\section{Conflicts of Interest}

The authors declare that there are no conflicts of interest regarding the publication of this paper.

\section{Acknowledgments}

The authors gratefully acknowledge the financial support for this study from the project of the National Natural Science
Foundation of China (Grant No. 51508236), the Natural Science Foundation of Jiangsu Province (Grant No. BK20150519), the China Postdoctoral Science Foundation (Grant No. 2015M580397), and the Research Foundation for Advanced Talents of Jiangsu University (Grant No. 15JDG172).

\section{References}

[1] L. C. Heyer, "Swell, stiffness and strength of expansive soilrubber (ESR) mixtures at various scales: effect of specimen and rubber particle sizes," Masters thesis, Colorado State University, Fort Collins, CO, USA, 2012.

[2] H. Cetin, M. Fener, and O. Gunaydin, "Geotechnical properties of tire-cohesive clayey soil mixtures as a fill material," Engineering Geology, vol. 88, no. 1-2, pp. 110-120, 2006.

[3] K. Adalier and A. Pamuk, "On the important mechanical properties of rubber-sand," Advanced Materials Research, vol. 685 , pp. 8-14, 2013.

[4] P. Anbazhagan, M. Mamatha, P. Soumyashree et al., "Laboratory characterization of tyre crumbs soil mixture for developing low cost damping materials," International Journal of Earth Sciences and Engineering, vol. 4, no. 6, pp. 63-66, 2011.

[5] S. Hamid, T. Habib, H. Mouloud, and A. Asroun, "Geotechnical properties of rubber tires and sediments mixtures," Engineering, Technology \& Applied Science Research, vol. 4, no. 2, pp. 618-624, 2014.

[6] S. Yoon, M. Prezzi, N. Z. Siddiki, and B. Kim, "Construction of a test embankment using a sand-tire shred mixture as fill material," Waste Management, vol. 26, no. 9, pp. 1033-1044, 2006.

[7] H.-H. Tsang, "Seismic isolation by rubber-soil mixtures for developing countries," Earthquake Engineering \& Structural Dynamics, vol. 37, no. 2, pp. 283-303, 2008.

[8] A. M. Abdelhaleem, R. M. EL-Sherbiny, H. Lotfy et al., "Evaluation of rubber/sand mixtures as replacement soils to mitigate earthquake induced ground motions," in Proceedings of the 18th Internationaln Conference on Soil Mechanics and Geotechnical Engineering, pp. 3163-3166, Paris, France, September 2013.

[9] T. B. Edil and P. J. Bosscher, "Engineering properties of tire chips and soil mixtures," Geotechnical Testing Journal, vol. 17, no. 4, pp. 453-464, 1994.

[10] G. J. Foose, C. H. Benson, and P. J. Bosscher, "Sand reinforced with shredded waste tires," Journal of Geotechnical Engineering, vol. 122, no. 9, pp. 760-767, 1996.

[11] A. Edinçliler, G. Baykal, and A. Saygıll, "Influence of different processing techniques on the mechanical properties of used tires in embankment construction," Waste Management, vol. 30, no. 6, pp. 1073-1080, 2010.

[12] L. H. Li, H. L. Xiao, H. M. Tang et al., "Shear performance optimizing of tire shred-sand mixture," Rock and Soil Mechanics, vol. 34, no. 4, pp. 1063-1067, 2013, in Chinese.

[13] S. M. Anvari, I. Shooshpasha, and S. S. Kutanaei, "Effect of granulated rubber on shear strength of fine-grained sand," Journal of Rock Mechanics and Geotechnical Engineering, vol. 9, no. 5, pp. 936-944, 2017.

[14] T. Tanchaisawat, D. T. Bergado, P. Voottipruex, and K. Shehzad, "Interaction between geogrid reinforcement and tire chip-sand lightweight backfill," Geotextiles and Geomembranes, vol. 28, no. 1, pp. 119-127, 2010.

[15] G. Mahmoud, "Shear strength characteristics of sand-mixed with granular rubber," Geotechnical and Geological Engineering, vol. 22, no. 3, pp. 401-416, 2004. 
[16] H. Sellaf, H. Trouzine, M. Hamhami, and A. Asroun, "Geotechnical properties of rubber tires and sediments mixtures," Engineering, Technology \& Applied Science Research, vol. 4, no. 2, pp. 618-624, 2014.

[17] M. Hyodo, S. Yamada, R. Orense et al., "Undrained cyclic shear properties of tire chip-sand mixtures," in Proceedings of the International Workshop on Scrap Tire Derived Geomaterials-Opportunities and Challenges, pp. 187-196, Yokosuka, Japan, March 2007.

[18] T. Uchimura, N. Chi, S. Nirmalan et al., "Shaking table tests on effect of tire chips and sand mixture in increasing liquefaction resistance and mitigating uplift of pipe," in Proceedings of the International Workshop on Scrap Tire Derived Geomaterials-Opportunities and Challenges, pp. 179-186, Yokosuka, Japan, March 2007.

[19] T. Kaneko, R. P. Orense, M. Hyodo, and N. Yoshimoto, "Seismic response characteristics of saturated sand deposits mixed with tire chips," Journal of Geotechnical and Geoenvironmental Engineering, vol. 139, no. 4, pp. 633-643, 2013.

[20] B. Li, M. Huang, X. Zeng et al., "Dynamic behavior and liquefaction analysis of recycled-rubber sand mixtures," Journal of Materials in Civil Engineering, vol. 28, no. 11, article 04016122, 2016, in Chinese.

[21] P. Promputthangkoon and A. Hyde, "Compressibility and liquefaction potential of rubber composite soils," in Proceedings of the International Workshop on Scrap Tire Derived Geomaterials-Opportunities and Challenges, pp. 161-170, Yokosuka, Japan, March 2007.

[22] L. H. Li, H. L. Xiao, H. M. Tang et al., "Dynamic properties variation of tire shred-soil mixtures," Rock and Soil Mechanics, vol. 35, no. 2, pp. 359-364, 2014, in Chinese.

[23] M. S. Mashiri, J. S. Vinod, and M. N. Sheikh, "Liquefaction potential and dynamic properties of sand-tyre chip (STCh) mixtures," Geotechnical Testing Journal, vol. 39, no. 1, pp. 69-79, 2016.

[24] N. Shariatmadari, M. Karimpour-Fard, A. Shargh et al., "Evaluation of liquefaction potential in sand-tire crumb mixtures using the energy approach," International Journal of Civil Engineering, vol. 17, no. 2, pp. 181-191, 2019.

[25] American Society for Testing Materials, ASTM D627008(2012), Standard Practice for Use of Scrap Tires in Civil Engineering Applications, American Society for Testing Materials, West Conshohocken, PA, USA, 2012.

[26] Codeofchina Inc., Standard for Soil Test Method, GB/T 501231999, Codeofchina Inc., Beijing, China, 2007, in Chinese.

[27] P. Castaldo, D. Gino, V. I. Carbone, and G. Mancini, "Framework for definition of design formulations from empirical and semi-empirical resistance models," Structural Concrete, vol. 19, no. 4, pp. 980-987, 2018.

[28] M. Holicky, J. V. Retief, and M. Sikora, "Assessment of model uncertainties for structural resistance," Probabilistic Engineering Mechanics, vol. 45, pp. 188-197, 2015.

[29] M. Sykora, M. Holicky, and J. Krejsa, "Model uncertainty for shear resistance of reinforced concrete beams with shear reinforcement according to EN 1992-1-1," Transactions of the VŠB-Technical University of Ostrava, Civil Engineering Series, vol. 23, pp. 150-159, 2015. 


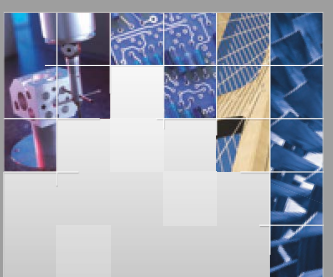

\section{Enfincering}
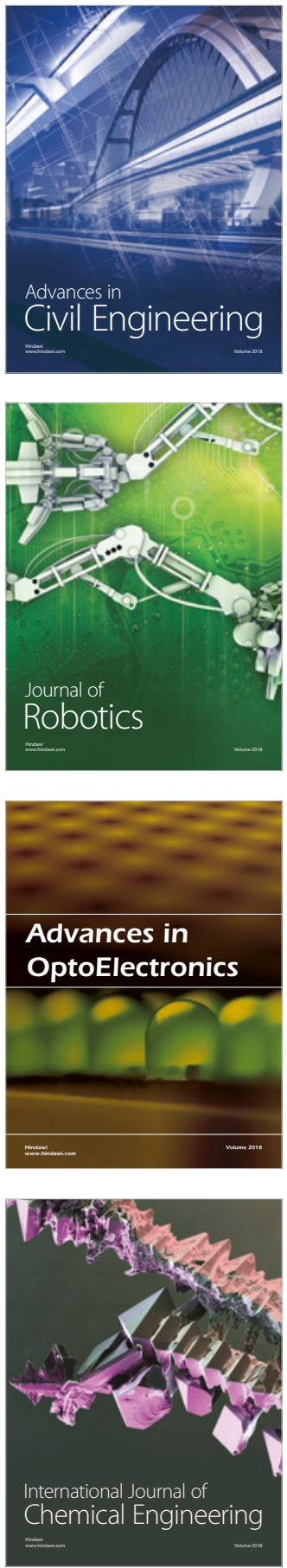

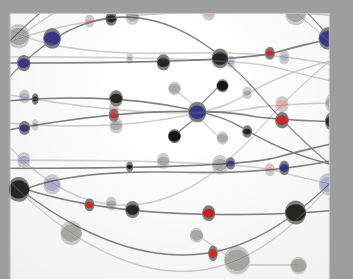

\section{Rotating \\ Machinery}

The Scientific World Journal

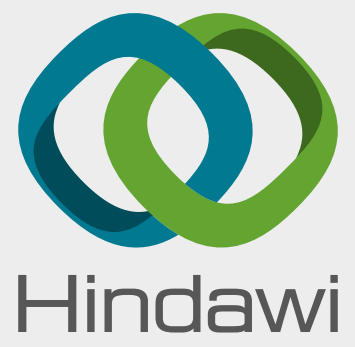

Submit your manuscripts at

www.hindawi.com
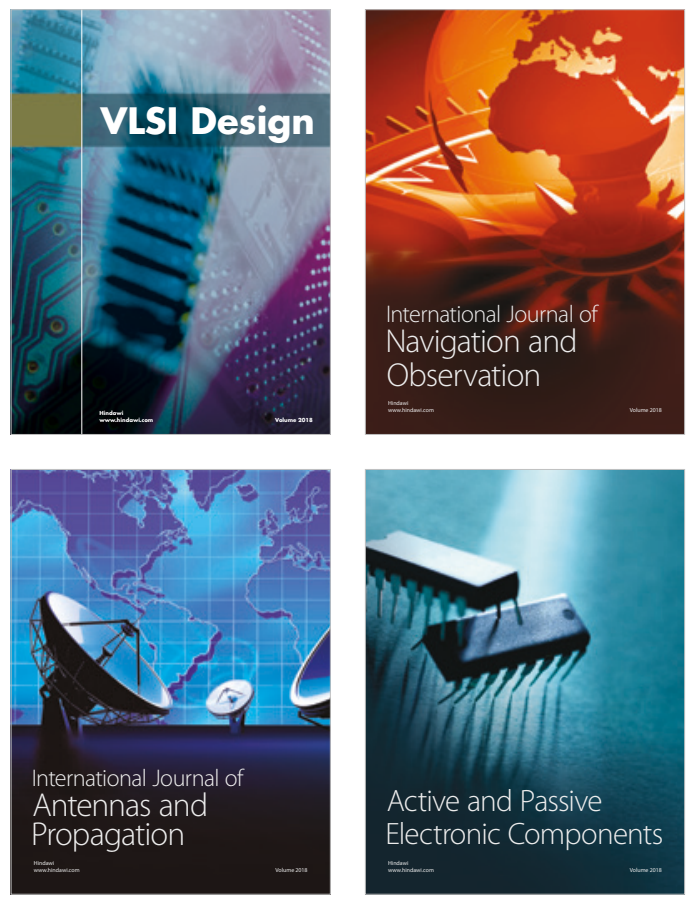
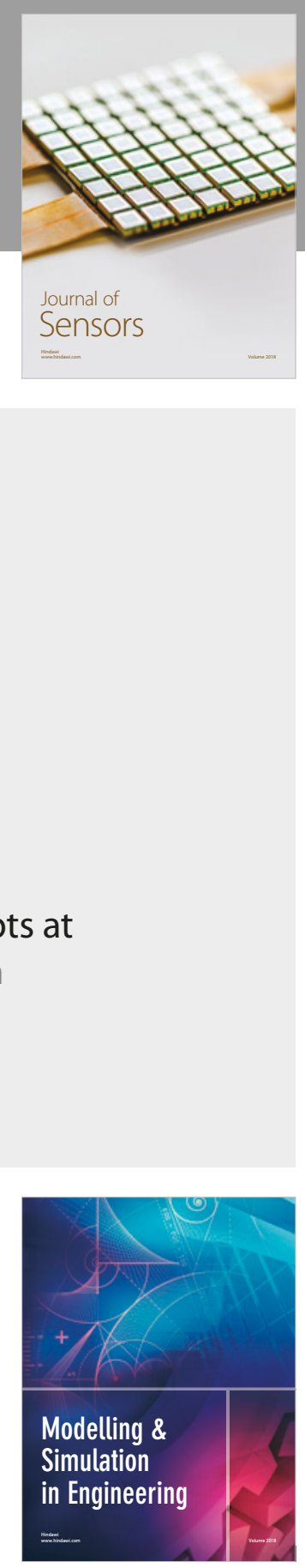

\section{Advances \\ Multimedia}
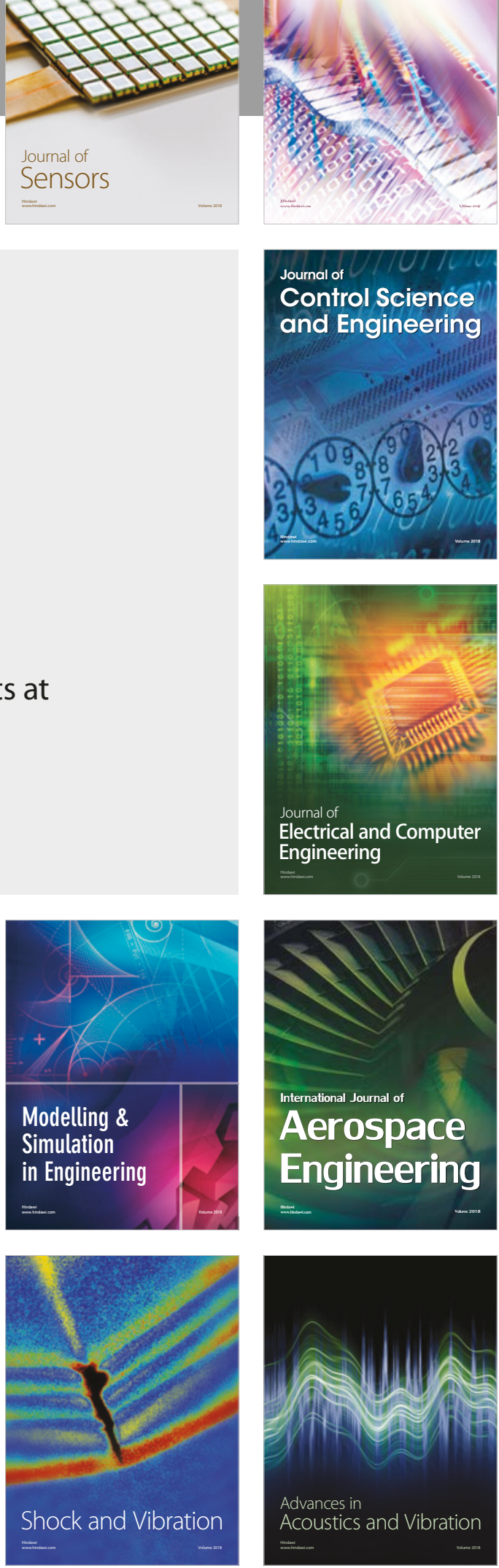